\title{
Comparison of Subthalamic Nucleus vs. Globus Pallidus Interna Deep Brain Stimulation in Terms of Gait and Balance; A Two Year Follow-Up Study
}

\author{
Ozkan CELIKER ${ }^{1 *}$, Goksemin DEMIR ${ }^{2}$, Murat KOCAOGLU ${ }^{1}$, Filiz ALTUG $^{3}$, Feridun ACAR ${ }^{1}$ \\ ${ }^{1}$ Pamukkale University, Department of Neurosurgery, Denizli, Turkey \\ ${ }^{2}$ Pamukkale University, Department of Neurosurgery Neurology, Denizli, Turkey \\ ${ }^{3}$ Pamukkale University, School of Physical Therapy and Rehabilitation, Denizli, Turkey \\ *Ozkan Celiker and Goksemin Demir have equally contributed to the study. \\ Corresponding author: Goksemin DEMIR gdemir@pau.edu.tr
}

\section{ABSTRACT}

AIM: To compare the effects of subthalamic nucleus (STN) and globus pallidus interna (GPi) deep brain stimulation (DBS) on the motor outcome, gait and balance function, fall risk (FR), and non-motor symptoms in patients with advanced Parkinson's disease (PD).

MATERIAL and METHODS: We randomized patients with advanced PD with the indication of DBS to undergo either STN or GPi DBS and followed them for 2 years. We collected data at baseline and postoperative 6, 12, and 24 months. We compared changes in the Unified Parkinson's Disease Rating Scale (UPDRS) score, timed gait tests, posturography, non-motor symptom questionnaire (NMSQuest), hospital anxiety and depression (HAD) scale, and levodopa equivalent dose (LED).

RESULTS: We enrolled and randomized 12 patients to receive either STN $(n=6)$ or GPi $(n=6)$ DBS. Postoperative motor outcomes were significantly improved in both groups $(p<0.05)$. In both groups, timed gait tests exhibited better performance in mobility; however, patients receiving GPi DBS performed better than those receiving STN DBS in the timed gait tests $(p<0.05)$. Furthermore, the posturographic evaluation demonstrated a significant elevation in the FR in the STN group $(p<0.05)$.

CONCLUSION: Both STN and GPi DBS are equally effective in alleviating disabling motor complications. However, seemingly, STN DBS could cause more gait and balance problems; hence, a tailored approach seems to be more appropriate in the target selection.

KEYWORDS: Advanced Parkinson's disease, Subthalamic nucleus, Globus pallidus interna, Deep brain stimulation

\section{INTRODUCTION}

$\mathrm{I}$ n patients with advanced idiopathic Parkinson's disease (PD), deep brain stimulation (DBS) is a well-established treatment option. Previously, randomized studies have revealed that treatment with subthalamic nucleus (STN) DBS is superior to the best medical therapy for improving the motor function and quality of life for patients with advanced PD (8). Both STN and globus pallidus interna (GPi) are accepted tar- gets for DBS. Although the motor outcomes after STN and GPi DBS are similar, apparently, non-motor factors could affect the target selection. In addition, although both STN and GPi stimulation markedly improve postural instability and gait disorder (PIGD), contradicting studies have revealed that patients experienced more frequent falls and gait disturbance in the first 3 months postoperatively (4). Moreover, some long-term studies reported that the gait function worsened in patients with PD undergoing STN DBS $(13,16,17,22,23)$. For instance,
Ozkan CELIKER (10): 0000-0003-4762-8420

Goksemin DEMIR (1): 0000-0001-8068-9060

Murat KOCAOGLU (1) : 0000-0002-4276-7897
Filiz ALTUG (1): 0000-0002-4287-8562

Feridun ACAR (10): 0000-0002-6964-087X 
Castrioto reported that, despite sustained improvement in tremor and bradykinesia, a progressive deterioration occurred in axial motor and postural scores over time (5). These results imply that the long-term progression of PIGD characteristics might be different with GPi stimulation than with STN stimulation and that GPi is a better target for patients with considerable balance and gait problems.

Of note, axial symptoms and balance issues are the least improved symptoms with DBS and can get worse because of either the selected target or disease progression. Thus, this prospective study aims to compare the motor outcomes, gait function, and fall risk (FR) of GPi and STN DBS, as well as changes in the levodopa equivalent dose (LED), emotional status, non-motor symptoms, activities of daily living, and disability.

\section{- PATIENTS and METHODS}

\section{Patients and Study Design}

In this study, we enrolled patients with idiopathic PD, who were diagnosed as stage $\geq 2$ based on the Hoehn and Yahr disability scale, had a considerable response to levodopa (at least $40 \%$ improvement in "off" Unified Parkinson's Disease Rating Scale (UPDRS) scores after L-dopa), and had persistent and disabling symptoms, such as motor fluctuations and dyskinesia, despite optimal medical therapy. We randomly assigned all patients to proceed to either pallidal or subthalamic stimulation DBS and followed them for 24 months after surgery and assessed at 6, 12, and 24 months postoperatively.

This study protocol was approved by the local ethics committee, and we obtained informed consent from each patient.

\section{Evaluation}

One of the results was the change in UPDRS-III from baseline to 24 months among patients receiving STN and GPi DBS with medication. For the postoperative baseline evaluation, we performed UPDRS-III at the "off" state following 12-h overnight withdrawal of antiparkinsonian medication and at the "on" state after $1 \mathrm{~h}$ of taking 1.5-fold of the usual morning LED. Postoperatively at 6,12 , and 24 months, we repeated UPDRS-III at the DBS "on" medication "on" state.

The outcomes of the gait and balance function were assessed using the timed 25-foot walk test, timed up and go test, the 30-s chair stand test, and posturography at the DBS "on" medication "on" state by study-site personnel and independently by movement-disorder clinicians who were blinded to study-group assignments.

a) Timed 25-foot walk test: $A$ quantitative mobility performance test based on a timed 25-foot walk. The time was measured from the initiation of the instruction to start and ended when a patient had reached the 25-foot mark.

b) Timed up and go test: A simple test used to assess patients' mobility that needs both static and dynamic balance. In this test, a patient was asked to stand from a standard armchair, walk $3 \mathrm{~m}$, turn around, walk back to the chair, and sit down. Using a stopwatch, the time taken for the task was recorded. The time required to complete the task was interpreted as follows: $\leq 10 \mathrm{~s}$, normal; $\leq 20 \mathrm{~s}$, good mobility without gait aid; and $\leq 30 \mathrm{~s}$, requires gait aid. Of note, a score of $\geq 14 \mathrm{~s}$ has been known to suggest a high risk of falls (25).

c) The 30-s chair stand test: It aims to test the leg strength and dynamic balance through a repeated sitting to standing activity. In this test, a patient was asked to sit on a standard chair with a straight back without arm rests (17), place hands on the opposite shoulder crossed at the wrist, rise to a full standing position, sit back down, and repeat the same sequence for $30 \mathrm{~s}$. The number of times the patient attained a full standing position was counted for $30 \mathrm{~s}$. A score of $<8$ stands was associated with a lower level of functional mobility and balance (14).

d) Posturographic evaluation: This assessment is performedusing a computed posturography system (Tetrax, Sunlight Medical, Israel), which evaluates the static postural balance by recording vertical pressure fluctuations in four different power plates. Input from the plates is integrated by a computer. In this test, a patient stood barefoot on the device, with arms freely hanging next to the body. The patient was instructed to begin by placing feet side by side on lined places of plates and not to speak or move during the task. Measurements were obtained in eight different conditions, each for $40 \mathrm{~s}$ as follows: (1) head straight, eyes open, on hard ground; (2) head straight, eyes closed, on hard ground; (3) head straight, eyes open, on soft ground (foam under the feet); (4) head straight, eyes closed, on soft ground; (5) head turned to the right, eyes closed, on hard ground; (6) head turned to the left, eyes closed, on hard ground; (7) neck fully extended, eyes closed, on hard ground; and (8) neck fully flexed, eyes closed, on hard ground.In addition, vestibular, visual, and somatosensorial inputs were documented in each of the eight different positions to assess the static postural balance and FR. All measurements were performed at the same time of the day $1-1.5 \mathrm{~h}$ following the levodopa dose, preoperatively and repeated at 6,12 , and 24 months after DBS surgery, the "DBS on medication on" state. For each patient, we calculated the FR, and a higher FR implied poorer postural performance. The measured FR ranged 0-35 was interpreted as low FR, 36-57 as moderate FR, and 58-100 as high FR.

Furthermore, we used the Schwab-England (S\&E) activities of daily living scale, hospital anxiety and depression (HAD) scale, and non-motor symptom questionnaire (NMSQuest) to assess the changes during the 24-month follow-up. Moreover, medication use was converted to LED for analysis and measured as a change from baseline to 24 months.

\section{Follow-Up}

All patients returned to the study site at 6,12 , and 24 months. We performed the entire baseline assessment blindly, which was repeated at 6,12 , and 24 months at the DBS "on" medication "on" state. Study neurologists directed the post- 
operative treatment to attain the optimal control of symptoms irrespective of the target of DBS. In addition, the management comprised adjustment of pharmacologic therapy (dose and regimen of dopaminergic and non-dopaminergic medications) and non-pharmacological treatments (e.g., physical therapy).

\section{Statistical Analysis}

In this study, we performed variance analyses, post-hoc Tukey test, and paired samples $t$-test using SPSS software version 17.0. We considered $p<0.05$ as statistically significant.

\section{RESULTS}

We enrolled 15 patients in this study but excluded one patient because the hardware was removed due to the internal pulse generator (IPG) site infection. In addition, two patients died during the follow-up period because of non-neurological reasons. Thus, we analyzed the data of 12 patients ( 10 females, and 2 males) in this study. Table I presents the demographic data of the study cohort.

\section{UPDRS}

Both preoperative and postoperative "on" state UPDRS motor scores were significantly reduced in both STN and GPi groups $(p<0.05)$. We observed the most considerable improvement in the first 6 months postoperatively, and for the next 18 months, patients in both groups either continued to improve or preserved their better motor status (Figure 1). Regarding motor scores, none of the groups was superior to the other.

\section{Timed 25-Foot Walk Test}

In both GPi and STN DBS groups, patients exhibited significantly better scores in the 25-foot walk test after 6 months postoperatively ( $p=0.000$; Figure 2$)$. In addition, their improvement was preserved at 12 and 24 months postoperatively.

\section{Timed Up and Go Test}

In both GPi and STN DBS groups, patients could complete the task more quickly postoperatively ( $p=0.000$; Figure 3$)$. In addition, their improvement was most significant in the

Table I: Demographic Features of the Study Cohort.

(A significant L-Dopa responsiveness was observed (>50\% improvement) in both groups ${ }^{\star}$ ).

\begin{tabular}{lccc}
\hline & GPi $(\mathbf{n}=6)$ & STN $(\mathbf{n}=6)$ & $\mathbf{p}$ \\
\hline Age (years) & $54 \pm 4.51$ & $56.16 \pm 9.6$ & \\
\hline Disease duration (years) & $10.16 \pm 3.12$ & $9 \pm 2$ & \\
\hline Age at disease onset (years) & $43.83 \pm 3.06$ & $47.16 \pm 11.19$ & \\
\hline H\&Y stage & $3.16 \pm 0.40$ & $3.00 \pm 0.89$ & \\
\hline UPDRS-III "on" & $22.50 \pm 6.65$ & $22.16 \pm 6.55$ & $\mathbf{0 . 0 0 0}^{*}$ \\
\hline UPDRS-III "off" & $49.00 \pm 13.57$ & $47.00 \pm 14.01$ & \\
\hline
\end{tabular}

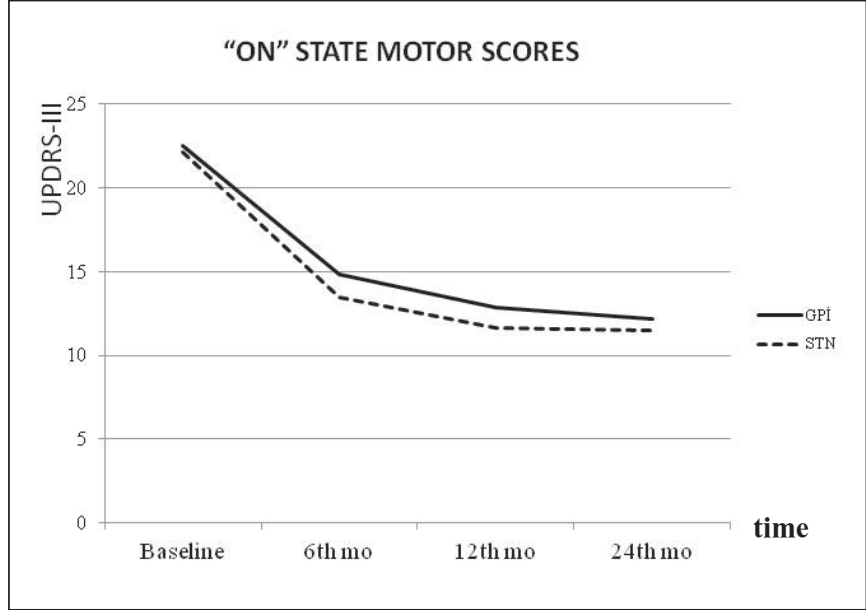

Figure 1: A significant improvement was observed in the "on" state UPDRS III scores after STN and GPi DBS $(p=0.000)$, which was sustained during the 2-year follow-up. The "on" state UPDRS scores were not different between two groups $(p=0.78)$.

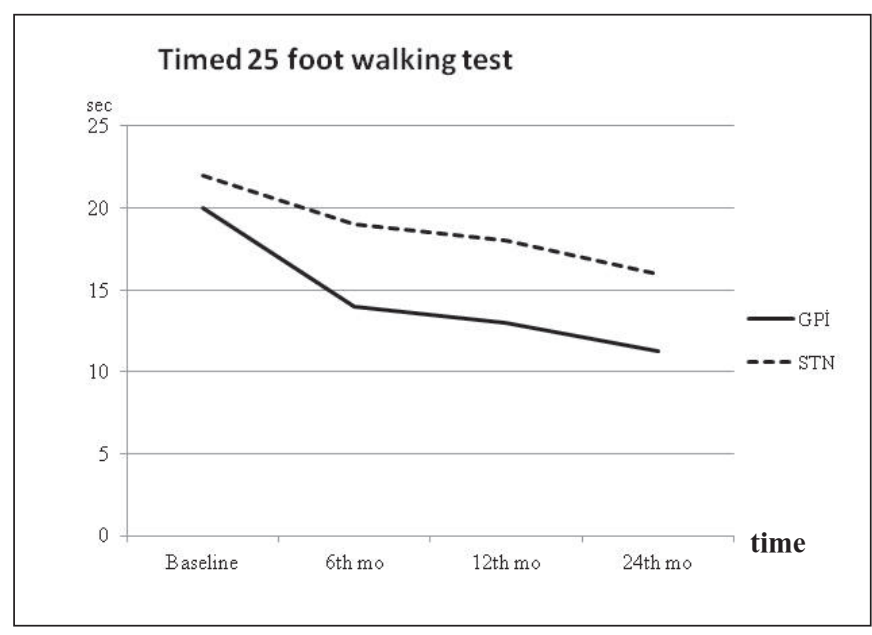

Figure 2: Both groups exhibited improvement in the timed 25foot walk test $(p=0.000)$, with no significant difference between the groups $(p=0.628)$. 
first 6 months and preserved during the 12- and 24-month controls. However, patients who received GPi DBS performed considerably better than patients receiving STN DBS $(p<0.05)$.

\section{0-s Chair Stand Test}

The 30-s chair stand test evaluated dynamic and static balance, and mobility was significantly better in both groups compared with preoperative scores $(p=0.000$; Figure 4). In particular, patients receiving GPi DBS exhibited a better performance in the first 6 months than patients receiving STN DBS $(p<0.05)$.

\section{Posturography}

In the GPi DBS group, we observed no significant change in the FR postoperatively compared with preoperative results. However, the FR in the STN group was significantly increased to $100 \%$ after 6 months ( $p<0.05$; Figure 5).

Furthermore, activities of daily living (ADL) improved in both groups; in particular, patients who received GPi DBS reported complete independence in their ADL (Table II). In contrast, patients who received STN DBS were less independent but apparently improved after DBS surgery. In both groups, patients were at the H\&Y stage 3 or 2 preoperatively, which improved to stage 1 at 6 and 12 months after GPi DBS and remained as such at 24 months $(p=0.000)$. In the STN DBS group, a significant improvement was observed at the H\&Y stage at 6 months, which was retained until 24-month control $(p=0.000)$. However, patients who received GPi DBS exhibited better improvement than patients receiving STN DBS $(p<$ 0.05). In addition, postoperative HAD scores for depression and anxiety were significantly improved in both groups $(p=$ 0.00); however, patients receiving GPi DBS were less anxious and depressed, especially in the early postoperative period, compared with the STN DBS group $(p<0.05$; Table II). All patients answered the 30 -item questionnaire preoperatively.

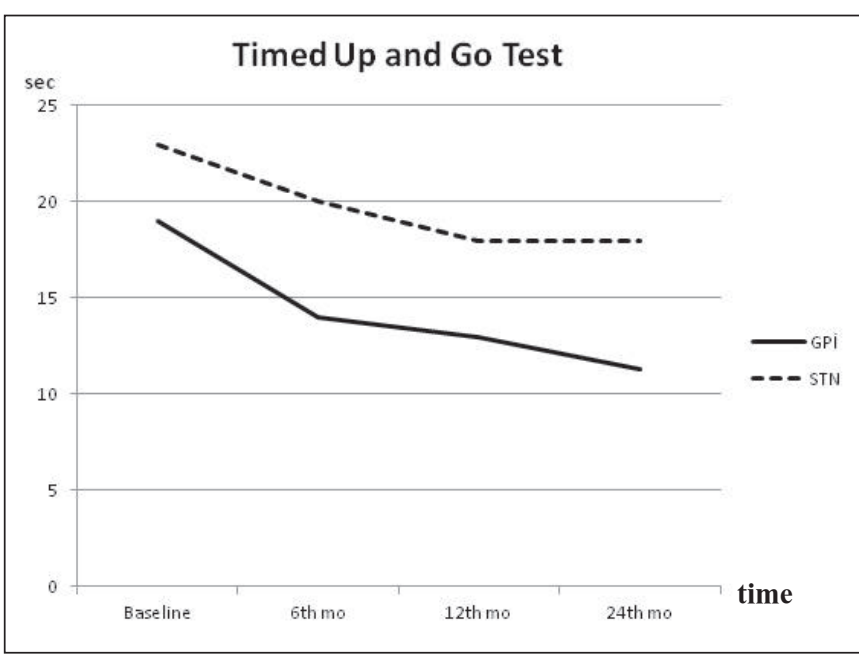

Figure 3: Both groups exhibited improvement in the TUG test postoperatively; however, patients receiving GPi DBS completed the task quicker than those receiving STN DBS $(p=0.000)$. This improvement was most significant in the first 6 months and preserved during the 12- and 24-month controls.
NMSQuest scores were $13.16 \pm 2.03$ in the GPi DBS group and $12.21 \pm 1.06$ in the STN DBS group. The most frequent NMSs in both groups were feeling sad or blue (GPi DBS, $83 \%$; STN DBS, $100 \%)$, urinary urge (83\%), feeling anxious/panicky $(66 \%)$, nocturia $(66 \%)$, constipation $(66 \%)$, falling $(66 \%)$, and sleep problems $(66 \%)$ in both groups. Postoperatively, all patients reported fewer NMSs than preoperatively, and the most significant decrease was noticed in depression and anxiety symptoms, sleep problem urgency, and nocturia $(p<$ 0.05).

Regarding L-dopa reduction, no significant decline was observed in the total LED in patients receiving GPi DBS; conversely, patients receiving STN DBS required less

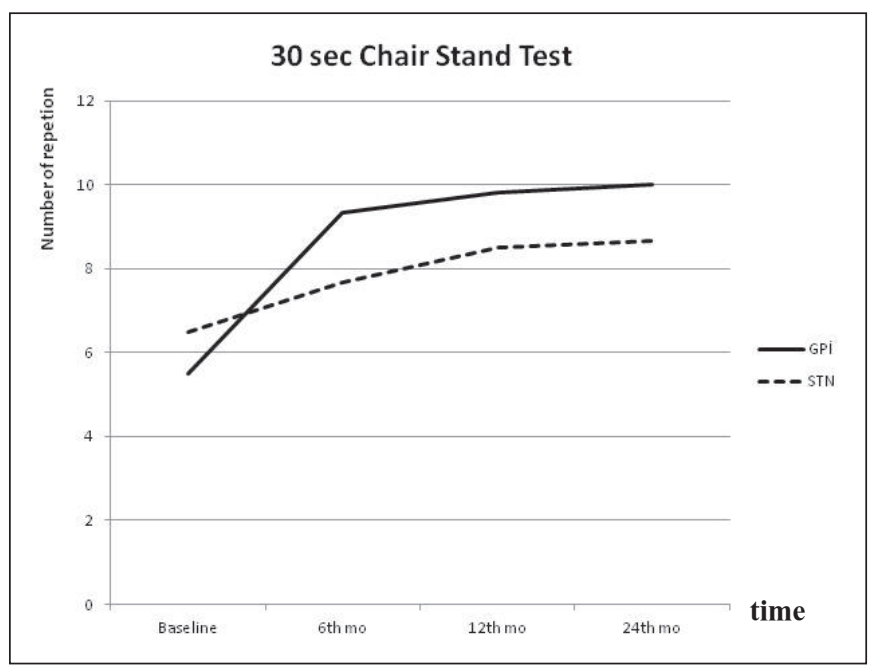

Figure 4: Both groups exhibited improvement in the 30-s chair stand test, along with better functional mobility and balance $(p=0.000)$. Moreover, a significant improvement in the GPi DBS group was better than that in the STN DBS group, especially in the early postoperative period $(p<0.05)$.

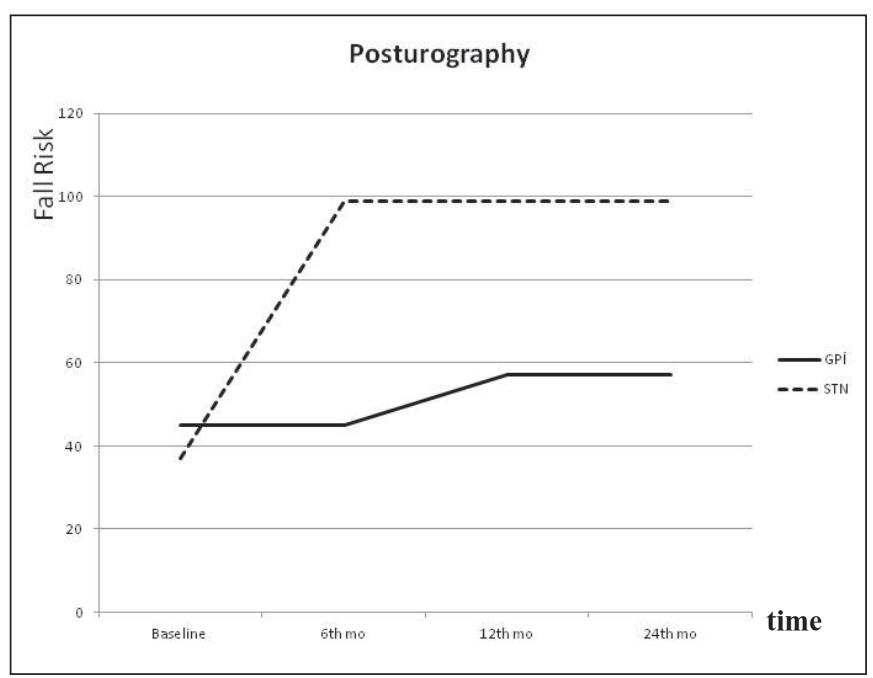

Figure 5: Posturography revealed a considerable increase in the fall risk in the STN DBS group 6 months postoperatively $(p<0.05)$. 
dopaminergic treatment even in the first 6 months (Table II). During the follow-up, LED tended to decline, and patients who received STN DBS used $73 \%$ less dopaminergic drugs at the end of 2 years.

\section{DISCUSSION}

In this study, we compared the motor outcomes of GPi DBS and STN DBS in patients with advanced PD with disabling motor complications. The findings revealed that both targets effectively improved the motor scores immediately postoperatively, and the benefit of the motor function was stable during the 2-year follow-up. Corroborating previous studies, we observed no considerable difference between the two surgical targets. Previously, bilateral pallidal stimulation was reported as effective as subthalamic stimulation in attaining better motor function $(3,10)$. Likewise, a recent meta-analysis reported that GPi and STN improved the motor function, with no difference in the therapeutic efficacy for PD between both targets (18). However, a multicenter study assessing the responsiveness to GPi or STN DBS according to motor subtypes reported that tremor-dominant patients might exhibit a higher response to GPi DBS regarding gait, whereas patients with PIGD exhibited overall less benefit from DBS irrespective of the stimulation target (15).

This study revealed that mobility performance, based on the timed 25-foot walk test, improved in both groups postoperatively. Although both STN and GPi DBS groups exhibited similar performance in this test, other tests assessing patients' mobility, which required both dynamic and static balance, revealed considerably better outcomes in the GPi DBS group postoperatively. Furthermore, static posturography revealed that patients who received STN DBS were more prone to fall. The increased FR was considered as a supporting result of relatively less improved mobility tests that needed both dynamic and static balance in the STN DBS group. These results corroborate previous studies comparing the long-term motor outcomes after undergoing GPi and STN DBS $(10,19,20,28,29)$. During the natural course of PD, a progressive loss of the benefit on axial signs can be expected over time, but the progression of balance and gait deficits apparently varied with the DSB site selection $(5,9,21)$. A meta-regression analysis of the DBS effect on gait and balance revealed that balance and gait initially improved with DBS in the "on" medication state, but were worse than the preoperative "on" medication state in the STN DBS group by 2 years, whereas no deterioration was reported in the postural stability and gait in the GPi DBS group (27). Castrioto reported that, although the stimulation-induced motor improvement was sustained overall at 10 years, axial signs revealed the most progressive decline in the STN DBS "on" medication "on" state over the years (5). In addition, St. George et al. reported that balance did not improve beyond the best medically treated state preoperatively and both clinical balance testing in the DBS "off" medication "off" state and self-reported balance confidence postoperatively exhibited better performance in the GPi DBS than in the STN DBS group $(26,27)$.

Overall, previous studies and our results revealed that the benefits to posture and gait are not sustained to the similar extent as the benefits to cardinal symptoms in the longterm. Although this study is limited by small sample size, the results suggested that the GPi could be a superior site to the STN in sustaining the postural stability and gait function in combination with levodopa.

Both depression and anxiety are frequently observed in patients with PD in the long-term medical management $(1,32)$. The findings of this prospective study related to nonmotor symptoms revealed that almost all patients reported depressive and anxious feelings in NMSQuest preoperatively.

Table II: Significant Improvement in the H\&Y Staging, Activities of Daily Living (ADL), and Hospital Anxiety Depression Scale (HAD) Scores Postoperatively. A Considerable Reduction was Observed in the Total LED in the STN DBS Group

\begin{tabular}{|c|c|c|c|c|c|c|c|}
\hline & & Baseline & $6^{\text {th }} \mathrm{mo}$ & $12^{\text {th }} \mathrm{mo}$ & $24^{\text {th }} \mathrm{mo}$ & & \\
\hline & & $X \pm S D$ & $X \pm S D$ & $X \pm S D$ & $X \pm S D$ & p & $\mathbf{p}^{*}$ \\
\hline \multirow{2}{*}{ H\&Y } & GPi & $3.16 \pm 0.4$ & $2.16 \pm 0.4$ & $1.66 \pm 0.81$ & $1.66 \pm 0.81$ & 0.000 & \multirow{2}{*}{$0.066^{\star}$} \\
\hline & STN & $3 \pm 0.89$ & $2.33 \pm 0.81$ & $2.16 \pm 0.98$ & $2.16 \pm 0.98$ & 0.000 & \\
\hline \multirow{2}{*}{ ADL } & GPi & $48.3 \pm 11.69$ & $70 \pm 12.64$ & $85 \pm 12.24$ & $90 \pm 15.49$ & 0.000 & \multirow{2}{*}{$0.002^{*}$} \\
\hline & STN & $56.66 \pm 20.65$ & $70 \pm 18.97$ & $75 \pm 22.58$ & $78.3 \pm 20.4$ & 0.000 & \\
\hline \multirow{2}{*}{$\begin{array}{l}\text { HAD depression } \\
\text { score }\end{array}$} & GPi & $12.3 \pm 5.46$ & $7.66 \pm 5.27$ & $5.83 \pm 4.95$ & $5.66 \pm 4.36$ & 0.000 & \multirow{2}{*}{$0.03^{*}$} \\
\hline & STN & $9.6 \pm 3.44$ & $7.5 \pm 4.72$ & $7.1 \pm 4.4$ & $6.8 \pm 4.53$ & 0.000 & \\
\hline \multirow{2}{*}{$\begin{array}{l}\text { HAD anxiety } \\
\text { score }\end{array}$} & GPi & $13 \pm 3.22$ & $7.83 \pm 4.99$ & $7.0 \pm 3.74$ & $6.83 \pm 2.71$ & 0.000 & \multirow{2}{*}{$0.021^{*}$} \\
\hline & STN & $9.5 \pm 3.61$ & $8.66 \pm 4.76$ & $7.83 \pm 4.21$ & $7.83 \pm 4.53$ & 0.000 & \\
\hline \multirow{2}{*}{$\begin{array}{l}\text { Total LED } \\
\text { dosage }\end{array}$} & GPi & $965.5 \pm 398.7$ & $883.1 \pm 240.7$ & $744 \pm 300.7$ & $706.0 \pm 343.6$ & 0.247 & \multirow{2}{*}{$0.005^{\star}$} \\
\hline & STN & $860.5 \pm 606.87$ & $585.4 \pm 348.8$ & $320.6 \pm 239.3$ & $235.5 \pm 212.9$ & 0.012 & \\
\hline
\end{tabular}

${ }^{*} p$ values indicate the significance between the two groups. 
Postoperatively, fewer patients reported depressive and anxious feelings in NMSQuest, and HAD scores were also improved in both groups. However, group comparisons did not reveal a considerable difference, suggesting a distinction between two targets. In previous studies, results about the effect of STN DBS were varied but were associated with worsening, and GPi DBS was associated with improvement of depression in a direct comparison to STN DBS (10); it also suggested that dopamine withdrawal, mesolimbic dopaminergic denervation, or a direct effect of STN DBS could be accountable for the worsening of depression.

Typically, more than half of the patients reported urinary symptoms, the most common being nocturia, urgency, and frequency (31). In this study, $83 \%$ of the patients reported urgency, and $66 \%$ reported nocturia preoperatively,with markedly decreased complaints postoperatively in both groups. Although the effect of GPi on urinary dysfunction remains unclear, STN DBS has been demonstrated to improve bladder symptoms with decreased detrusor hyperreflexia and increased bladder capacity, which might be secondary to the modulation of bladder afferents and central sensory processing $(11,24,30)$.

In most patients with PD (74\%-98\%), variable sleep problems occurred, such as insomnia, sleep fragmentation, excessive daytime sleepiness, rapid eye movement sleep behavioral disorder, vivid nightmares, and restless legs (2). In this study, both groups reported vivid dreams, acting out of a dream, and restless legs preoperatively. Postoperatively, both groups reported apparently fewer sleep-related problems. Sleep problems in patients with PD are multifactorial; disease progression, motor fluctuations, degeneration, and medications all contribute to sleep disturbances. Although the effect of GPi DBS on sleep remains partially elucidated, to date, STN DBS improves objective polysomnographic measures of sleep and sleep quality $(6,7,33)$. Furthermore, a direct comparison of STN DBS with medical treatment suggested that STN DBS probably acted only by reducing motor symptoms and did not modulate central sleep (12).

\section{CONCLUSION}

Both STN and GPi are equally effective targets for treating motor dysfunction in well-selected patients with advanced PD with disabling motor complications or medically intractable tremor without considerably cognitive or psychiatric problems. STN DBS facilitates a higher reduction of medication but could be related to the increased FR and worsening of some nonmotor symptoms, whereas GPi DBS could lead to less gait and balance issues. Hence, target selection could be tailored depending on the goals of DBS because one approach might not fit all. If the objective is to reduce the medication, STN DBS could be preferred; however, if a patient has gait and balance problems predominantly, GPi DBS could be selected. Finally, this study recognizes the importance of attaining the proper balance between evidence-based and preferencebased selections of targets.

\section{REFERENCES}

1. Aarsland D, Larsen JP, Lim NG, Janvin C, Karlsen K, Tandberg E, Cummings JL: Range of neuropsychiatric disturbances in patients with Parkinson's disease. J Neurol Neurosurg Psychiatry 67:492-496, 1999

2. Amara AW, Standaert DG, Guthrie S, Cutter G, Watts RL, Walker HC: Unilateral subthalamic nucleus deep brain stimulation improves sleep quality in Parkinson's disease. Parkinsonism Relat Disord 18:63-68,2012

3. Anderson VC, Burchiel KJ, Hogarth P, Favre J, Hammerstad JP: Pallidal vs subthalamic nucleus deep brain stimulation in Parkinson disease. Arch Neurol 62:554-560,2005

4. Bakker M, Esselink RAJ, Munneke M, Limousin-Dowsey P, Speelman HD, Bloem BR: Effects of stereotactic neurosurgery on postural instability and gait in Parkinson's disease. Mov Disord 19:1092-1099,2004

5. Castrioto A: Ten-year outcome of subthalamic stimulation in Parkinson Disease. Arch Neurol 68:1550, 2011

6. Chahine LM, Ahmed A, Sun Z: Effects of STN DBS for Parkinson's disease on restless legs syndrome and other sleep-related measures. Park Relat Disord 17:208-211, 2011

7. Cicolin A, Lopiano L, Zibetti M, Torre E, Tavella A, Guastamacchia G, Terreni A, Makrydakis G, Fattori E, Lanotte MM, Bergamasco B, Mutani R: Effects of deep brain stimulation of the subthalamic nucleus on sleep architecture in parkinsonian patients. Sleep Med 5:207-210, 2004

8. Deuschl G: A randomized trial of deep-brain stimulation for Parkinson's disease. N Engl J Med 355:896-908, 2006

9. Fasano A, Romito LM, Daniele A, Piano C, Zinno M, Bentivoglio AR, Albanese A: Motor and cognitive outcome in patients with Parkinson's disease 8 years after subthalamic implants, Brain. 133:2664-2676,2010

10. Follett K, Weaver F, Stern M, Hur K, Harris CL, Luo P, Marks WJ, Rothlind J, Sagher O, Moy C, Pahwa R, Burchiel K, Hogarth P, Lai EC, Duda JE, Holloway K, Samii A, Horn S, Bronstein JM, Stoner G, Starr PA, Simpson R, Baltuch G, De Salles A, Huang GD, Reda DJ: Pallidal versus subthalamic deep-brain stimulation for Parkinson's disease. N Engl J Med 362:2077-2091, 2010

11. Herzog J, Weiss PH, Assmus A, Wefer B, Seif C, Braun PM, Herzog H, Volkmann J, Deuschl G, Fink GR: Subthalamic stimulation modulates cortical control of urinary bladder in Parkinson's disease. Brain 129:3366-3375, 2006

12. Hjort N, Østergaard K, Dupont E: Improvement of sleep quality in patients with advanced Parkinson's disease treated with deep brain stimulation of the subthalamic nucleus. Mov Disord 19:196-199,2004

13. House P: Ten-year outcome of subthalamic stimulation in parkinson disease: A blinded evaluation. Yearb Neurol Neurosurg 2012:243-244, 2012

14. Jones CJ, Rikli RE, Beam WC: A 30-s chair-stand test as a measure of lower body strength in community-residing older adults. Res Q Exerc Sport 70:113-119, 1999

15. Katz M, San Luciano M, Carlson K, Luo P, Marks WJ, Larson PS,Starr PA, Follett KA, Weaver FM, Stern MB, Reda DJ, Ostrem JL: The differential effects of DBS target on motor subtypes in Parkinson's disease. Ann Neurol 77:710-719,2015 
16. Krack P, Batir A, Van Blercom N, Chabardes S, Fraix V, Ardouin C, Koudsie A, Limousin PD, Benazzouz A, LeBas JF, Benabid $A L$, Pollak P: Five-year follow-up of bilateral stimulation of the subthalamic nucleus in advanced Parkinson's Disease. N Engl J Med 349:1925-1934,2003

17. Liang GS, Chou KL, Baltuch GH, Jaggi JL, Loveland-Jones C, Leng L, Maccarone H, Hurtig H, Kolcher A, Stern MB, KleinerFisman G, Simuni T, Siderowf AD:Long-term outcomes of bilateral subthalamic nucleus stimulation in patients with advanced Parkinson's disease. Stereotact Funct Neurosurg 84:221-227, 2006

18. Liu Y, Li W, Tan C, Liu X, Wang X, Gui Y, Quin L, Deng F, Hu $C$, Chen L: Meta-analysis comparing deep brain stimulation of the globus pallidus and subthalamic nucleus to treat advanced Parkinson disease. J Neurosurg 121:709-718, 2014

19. Moro E, Lozano AM, Pollak P, Agid Y, Rehncrona S, Volkmann J, Kulisevsky J, Obeso JA, Albanese A, Hariz MI, Quinn NP, Speelman JD, Benabid AL, Fraix V, Mendes A, Welter ML, Houeto JL, Cornu P, Dormont D, Tornqvist AL, Ekberg R, Schnitzler A, Timmermann L, Wojtecki L, Gironell A, Rodriguez-Oroz MC, Guridi J, Bentivoglio AR, Contarino MF, Romito L, Scerrati M, Janssens M, Lang AE: Long-term results of a multicenter study on subthalamic and pallidal stimulation in Parkinson's disease. Mov Disord 25:578-586,2010

20. Odekerken VJ, van Laar T, Staal MJ, Mosch A, Hoffmann CF, Nijssen PC, Beute GN, van Vugt JP, Lenders MW, Contarino MF, Mink MS, Bour LJ, van den Munckhof P, Schmand BA, de Haan RJ, Schuurman PR, de Bie RM: Subthalamic nucleus versus globus pallidus bilateral deep brain stimulation for advanced Parkinson's disease (NSTAPS study): A randomised controlled trial. Lancet Neurol 12:37-44,2013

21. Rizzone MG, Fasano A, Daniele A, Zibetti M, Merola A, Rizzi L, Piano C, Piccininni C, Romito LM, Lopiano L, Albanese A: Long-term outcome of subthalamic nucleus DBS in Parkinson's disease: From the advanced phase towards the late stage of the disease? Park Relat Disord 20:376-381,2014

22. Rodriguez-Oroz MC, Obeso JA, Lang AE, Houeto J-L, Pollak P, Rehncrona S, Kulisevsky J, Albanese A, Volkmann J, Hariz MI, Quinn NP, Speelman JD, Guridi J, Zamarbide I, Gironell A, Molet J, Pascual-Sedano B, Pidoux B, Bonnet AM, Agid Y, Xie J, Benabid AL, Lozano AM, Saint-Cyr J, Romito L, Contarino M F, Scerrati M, Fraix V, Van Blercom N: Bilateral deep brain stimulation in Parkinson's disease: A multicentre study with 4 years follow-up. Brain 128:2240-2249, 2005

23. Schupbach WMM: Stimulation of the subthalamic nucleus in Parkinson's disease: A 5 year follow up. J Neurol Neurosurg Psychiatry 76:1640-1644, 2005
24. Seif C, Herzog J, van der Horst C, Schrader B, Volkmann J, Deuschl G, Juenemann KP, Braun PM: Effect of subthalamic deep brain stimulation on the function of the urinary bladder. Ann Neurol 55:118-120, 2004

25. Shumway-Cook A, Brauer S, Woollacott M: Predicting the probability for falls in community-dwelling older adults using the Timed Up \& Go Test. Phys Ther 80:896-903, 2000

26. St George RJ, Carlson-Kuhta P, Nutt JG, Hogarth P, Burchiel KJ, Horak FB: The effect of deep brain stimulation randomized by site on balance in Parkinson's disease. Mov Disord 29:949953, 2014

27. St. George RJ, Nutt JG, Burchiel KJ, Horak FB: A metaregression of the long-term effects of deep brain stimulation on balance and gait in PD. Neurology 75:1292-1299, 2010

28. Weaver FM, Follett K, Stern M, Hur K, Harris C, Marks WJ, Rothlind J, Sagher O, Reda D, Moy CS, Pahwa K, Burchiel K, Hogarth P, Lai EC, Duda JE, Holloway K, Samii A, Hom S, Bronstein J, Stoner G, Heemskerk J, Huang GD: Bilateral deep brain stimulation vs best medical therapy for patientswith advanced Parkinson disease: A randomized controlled trial. J Am Med Assoc 301:63, 2010

29. Weaver FM, Follett KA, Stern M, Luo P, Harris CL, Hur K, Marks WJ, Rothlind J, Sagher O, Moy C, Pahwa R, Burchiel K, Hogarth P, Lai EC, Duda JE, Holloway K, Samii A. Horn S, Bronstein JM, Stoner G, Starr PA, Simpson R, Baltuch G, De Salles A, Huang GD, Reda DJ: Randomized trial of deep brain stimulation for Parkinson disease: Thirty-six-month outcomes. Neurology 79:55-65, 2012

30. Winge K, Nielsen KK, Stimpel H, Lokkegaard A, Jensen SR, Werdelin L: Lower urinary tract symptoms and bladder control in advanced Parkinson's disease: Effects of deep brain stimulation in the subthalamic nucleus. Mov Disord 22:220 225, 2007

31. Winge K, Skau AM, Stimpel $H$, Nielsen KK, Werdelin L: Prevalence of bladder dysfunction in Parkinsons disease. Neurourol Urodyn 25:116-122, 2006

32. Zgaljardic DJ, Borod NC, Foldi NS, Mattis P: A review of the cognitive and behavioral sequelae of Parkinson's disease: Relationship to frontostriatal circuitry. Cogn Behav Neurol 16:193-210, 2003

33. Zibetti M, Torre E, Cinquepalmi A, Rosso M, Ducati A, Bergamasco B, Lanotte M, Lopiano L: Motor and nonmotor symptom follow-up in Parkinsonian patients after deep brain stimulation of the subthalamic nucleus. Eur Neurol 58:218223, 2007 